\title{
Effects of Warning and Information Labels on Consumption of Full-Fat, Reduced-Fat, and No-Fat Products
}

\author{
Brad J. Bushman \\ Iowa State University
}

\begin{abstract}
Participants in a taste test study were randomly assigned to 1 of 3 groups: warning label (e.g., "In this product, 90\% of the calories come from fat. Warning: The U.S. Surgeon General has determined that eating high fat food increases your risk of heart disease."'), information label (e.g., "In this product, 90\% of the calories come from fat."), and no label. Participants rated how much they wanted to taste full-, reduced-, and no-fat cream cheeses, and they chose 1 type to eat. People in the warning- and no-label groups wanted to taste the full-fat product more than those in the information-label group. People in the warning- and information-label groups were less likely to eat the full-fat product than those in the no-label group. People reacted to the warning label but avoided the full-fat product. For products with credible and familiar risks, information labels may be more effective than warning labels because they don't arouse reactance.
\end{abstract}

So great is man's hunger for forbidden food! Ovid, Metamorphoses

\begin{abstract}
Adam was but human - this explains it all. He did not want the apple for the apple's sake, he wanted it only because it was forbidden.
\end{abstract}

Mark Twain, Pudd'nhead Wilson

American society seems to be moving more and more toward the idea that warning labels are desirable for a variety of products, from fatty foods to Internet access paths. To avoid law suits, manufacturers now put warning labels on almost everything. For example, a Batman costume contains the following warning: "PARENT: Please exercise caution-FOR PLAY ONLY: Mask and chest plate are not protective: cape does not enable user to fly" (Broder, 1997).

There are two competing theories about the effects of warning labels on consumers: forbidden fruit and tainted fruit (Christenson, 1992). The term forbidden fruit comes from the Biblical account in which God, the ultimate authority figure, tells Adam and Eve to help themselves to any fruit in the Garden of Eden except the fruit from the tree of knowledge of good and evil. Adam and Eve ate the forbidden fruit anyway (perhaps because God told them not to eat it). If something is forbidden, people

I thank Brad Cave and Angela Stack for serving as experimenters.

Correspondence concerning this article should be addressed to Brad J. Bushman, Department of Psychology, Iowa State University, Ames, Iowa 50011-3180. Electronic mail may be sent to bushman@iastate.edu. may want it even more. For example, they may conclude, "Anything I shouldn't have is probably really fun to have."

In psychology, reactance theory (J. W. Brehm, 1966, 1972; S. S. Brehm \& Brehm, 1981; Wicklund, 1974) is based on this forbidden fruit idea. According to reactance theory, when an individual's freedom to engage in a particular behavior is threatened or eliminated, the individual will experience psychological reactance-an unpleasant motivational state that consists of pressures to re-establish the threatened or lost freedom. One method of re-establishing the freedom is to engage in the proscribed behavior. Social influence attempts can therefore backfire, in that pressure toward change created by the influence agent may induce the person to move in the direction opposite from the influence effort, sometimes called a "boomerang effect." Thus, if consumers perceive warning labels as a restriction on their freedom to use a given product, then reactance theory would predict that the labels will make consumers want the product even more. Warning labels should be especially likely to backfire if the warning is issued by an authoritative source (e.g., the U.S. Surgeon General), because messages from authoritative sources produce more pressure to comply with the behavioral admonition (e.g., Wicklund, 1974).

Tainted-fruit theory posits that warning labels should decrease the attractiveness of a given product because the product might harm the consumer. A warning from an authoritative source, such as the U.S. Surgeon General, should be especially effective in reducing the attractiveness of a product. The major responsibility of the U.S. Surgeon General is to warn the public about dangerous influences to their physical and mental health. Thus, a 
warning from the U.S. Surgeon General indicates that the fruit is not just tainted but is probably toxic.

Previous research has shown that warnings from authoritative sources are more likely to draw consumers than to repel them (e.g., Bushman \& Stack, 1996; Snyder \& Blood, 1992). Thus, we are faced with a dilemma-how to decrease attraction to harmful products without arousing reactance in consumers. One alternative to using warning labels is to use information labels. An example of an information label for a food product is "In this product, $90 \%$ of the calories come from fat." An example of a warning label for a food product is "In this product, 90\% of the calories come from fat. Warning: The U.S. Surgeon General has determined that eating high fat food increases your risk of heart disease." Both types of labels inform people about the product's fat content. However, the warning label has an additional component-it provides a behavioral admonition linked to a personal risk. This additional component might arouse reactance in consumers. Consumers might not want advice about their diets.

Whether a warning label makes a product a forbidden fruit or a tainted fruit may depend on the nature of the product. If the harmful effects of the product are wellknown, then an information label might be just as effective as a warning label. If the warning label arouses reactance in consumers, then an information label could be even more effective than a warning label. For products such as fatty foods, for example, it might not be necessary to warn consumers. Not only do high fat foods contribute to the development of obesity, but they also increase the risk of cardiovascular disease, stroke, cancer, hypertension, diabetes, and other degenerative diseases (e.g., Gershoff, 1995; Williams \& Worthington-Roberts, 1996). Americans spend more than $\$ 30$ billion each year trying to lose weight by dieting (Miller, 1989). Most people are well aware that dietary fat also increases the risk of cardiovascular and other diseases (e.g., Jones, Greaves, \& Iliffe, 1992). Thus, it may be enough to simply inform consumers about the product's fat content rather than warn them about what foods they should avoid.

Previous research has shown that information labels are less likely to draw viewers to violent media than are warning labels, especially if the warning is issued by the U.S. Surgeon General (Bushman \& Stack, 1996). One important difference between consuming fatty foods and consuming violent media is that it is easier for people to dismiss harmful effects of the latter. People often claim that although television violence has harmful effects on others, television violence doesn't affect them personally (Innes \& Zeitz, 1988). In contrast, it would be difficult for people to claim that although fatty foods clog other people's arteries, fatty foods don't affect them personally. Thus, warning labels on fatty foods might arouse reactance in consumers, but consumers might follow the behavioral admonition on the label anyway.
The present experiment tested the effects of warning and information labels on consumption of fatty foods. Participants were told that the study was part of a National Consumer Research project to evaluate different types of cream cheese. Three types of cream cheese were tested: regular or full-fat ( $90 \%$ fat), "light" or reduced-fat (64\% fat), and fat-free or no-fat ( $0 \%$ fat). Participants were randomly assigned to one of three groups: warning label (i.e., "In this product, $90 \%$ [ $64 \%$, or $0 \%$ ] of the calories come from fat. Warning: The U.S. Surgeon General has determined that eating high fat food increases your risk of heart disease."); information label (i.e., "In this product, $90 \%$ [ $64 \%$, or $0 \%$ ] of the calories come from fat.'), and no-label control. Participants rated how much they wanted to taste each type of cream cheese, and they selected one type to eat.

On the basis of reactance theory, I predicted that participants in the warning-label condition would want to taste the full-fat cream cheese more than would participants in the information-label condition. Although I expected the warning labels to increase people's desire to consume full-fat products, I did not expect them to increase people's actual consumption of full-fat products. The reason is that people cannot claim that they are immune to the harmful effects of fatty food. Thus, I expected participants in the warning- and information-label groups to choose the full-fat cream cheese less often than participants in the no-label condition. ${ }^{1}$ No difference was predicted between the warning- and information-label groups because the harmful effects of fatty food are well-known.

I used three different types of cream cheeses in the experiment to provide consumers with a choice of products, similar to what they might find at a grocery store. The predicted effects, however, were for the full-fat cream cheese. I did not expect warning and information labels to influence preference measures for the reduced-fat and no-fat products. Previous research has shown that people have more positive attitudes toward reduced-fat and nofat products than toward full-fat products (e.g., Aaron, Mela, \& Evans, 1994; Solheim, 1992; Stafleu, de Graaf, van Staveren, \& de Jong, 1994). Thus, consumers might consider warnings on reduced-fat and no-fat products to be irrelevant, perhaps because they perceive such products to have minimal health risks.

\section{Method}

\section{Participants}

Participants were 360 undergraduate psychology students (180 men, 180 women), who received extra course credit in exchange for their voluntary participation.

\footnotetext{
${ }^{1}$ Of course, if people don't choose the full-fat cream cheese, then they must choose the no-fat or reduced-fat cream cheeses. Thus, warning and information labels might also (indirectly) influence choices of no-fat and reduced-fat cream cheeses.
} 


\section{Design}

The study design was factorial, with variables of label condition (U.S. Surgeon General warning label, information label, no-label control), sex of participant, and type of cream cheese (full-fat, reduced-fat, fat free). The last variable involved repeated measures. There were 120 participants (60 men, 60 women) in each of the three label conditions.

\section{Procedure}

Each participant was tested individually. Participants were first given a cover sheet and consent form. The cover sheet stated that the study was part of a National Consumer Research Project to evaluate the quality and taste of different types of cream cheese. Participants were randomly assigned to one of three groups:

1. U.S. Surgeon General warning label. "In this product, $\%$ of the calories come from fat. Warning: The U.S. Surgeon General has determined that eating high fat food increases your risk of heart disease."

2. Information label. "In this product, ___ \% of the calories come from fat."

3. No-label control.

Three types of Philadelphia brand cream cheese were tested: regular (full-fat), "light" (reduced-fat), and fat free (no-fat). The percentages of calories from fat were $90 \%, 64 \%$, and $0 \%$ for the full-fat, reduced-fat, and fat free cream cheeses, respectively. The labels were printed in uppercase letters and were enclosed in asterisks. Participants in the warning- and information-label conditions were told, "The products have labels because the Human Participants Review Committee required us to tell people about the fat content of the products."

Participants rated how much they wanted to taste each type of cream cheese (i.e., full-fat, reduced-fat, and no-fat). Participants made responses along a 10-point Likert-type scale ranging from 1 (strongly disagree) to 10 (strongly agree) that they wanted to taste the cream cheese. Next, participants selected one type of cream cheese to taste. I used choice of cream cheese to measure actual behavior because in the "real world" (e.g., the grocery store) consumers also are given a choice of full-fat, reduced-fat, and no-fat cream cheeses. After tasting the cream cheese on a plain Lender's bagelette, participants rated the cream cheese they tasted on four dimensions: flavor, zest, texture, and aftertaste. Participants also provided an overall rating for the cream cheese. Participants made responses along a 10point Likert-type scale ranging from 1 (well below average) to 10 (well above average). Finally, participants were fully debriefed and thanked for their participation.

\section{Results}

\section{Desire to Taste the Cream Cheeses}

I used multivariate analysis of variance (Vasey \& Thayer, 1987) to test whether labels influenced participants' desire to taste the cream cheeses. The label effect was significant for the full-fat cream cheese but was non- significant for the reduced-fat and no-fat cream cheeses, $F_{\mathrm{S}}(2,354)=3.40,0.95$, and 0.17 , respectively (see Figure 1). As expected, participants in the no-label and warning-label conditions wanted to eat the full-fat cream cheese more than did participants in the information-label condition, $t(354)=2.56, p<.05, d=0.27$, and $t(354)$ $=1.72, p<.10, d=0.18$, respectively, although the latter comparison was not quite significant. There was no difference between the warning-label and no-label conditions, $t(354)=0.85, p>.05$. The interaction between label condition and cream cheese type was not significant, $F(4,706)=1.60, p>.05$, Wilks's $\lambda=0.98$.

I also found other effects less central to the hypotheses being tested. There was a significant interaction between the sex of the participant and the type of cream cheese, $F(2,353)=23.78, p<.05$. Men wanted to taste the fullfat cream cheese more than women did, whereas women wanted to taste the reduced-fat and no-fat cream cheeses more than men did, $F_{s}(1,354)=18.96,9.07$, and 42.16 , respectively, $p \mathrm{~s}<.05$.

\section{Choice of Cream Cheese}

I used analysis of variance (ANOVA) to test whether labels influenced which type of cream cheese participants selected to taste $(1=$ full-fat, $2=$ reduced-fat, $3=$ fat free). The same pattern of results was obtained when I used nonparametric analyses. The analysis revealed a significant effect for label condition, $F(2,354)=3.21$, $p<.05$. Participants in the warning- and informationlabel conditions selected lower fat cream cheeses than did participants in the no-label control condition, $t(354)=$ $2.30, p<.05, d=0.24$, and $t(354)=2.06, p<.05, d$

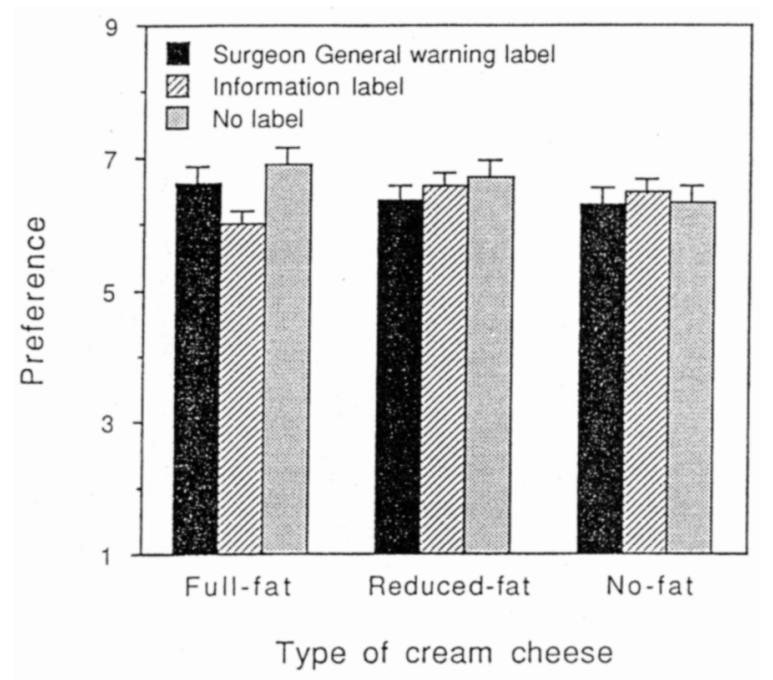

Figure 1. Effects of warning and information labels on desire to consume full-, reduced-, and no-fat products. Capped vertical bars denote one standard error. 
$=0.22$, respectively. The two label conditions did not differ, $t(354)=0.24, p>.05, d=0.03$. The percentage of participants selecting each type of cream cheese is depicted in Figure 2.

I also found other effects less central to the hypotheses being tested. Women selected lower fat cream cheeses more often than men did, $F(1,354)=49.01, p<.05$, $d=0.74$. Overall, $49 \%$ of men selected full-fat cream cheese, $23 \%$ selected reduced-fat cream cheese, and $28 \%$ selected no-fat cream cheese. In contrast, $18 \%$ of women selected full-fat cream cheese, $25 \%$ selected reduced-fat cream cheese, and $57 \%$ selected no-fat cream cheese.

\section{Cream Cheese Ratings}

I used ANOVA to analyze ratings of the overall quality of the various types of cream cheese. Because participants rated only one type of cream cheese, I performed a separate ANOVA for each type of cream cheese. No significant label condition effects were found in any of the analyses. There were sex differences in ratings of the full-fat and reduced-fat cream cheeses. Women gave full-fat and reduced-fat cream cheeses higher ratings than did men, $F(1$, $114)=4.31, p<.05, d=0.39$, and $F(1,80)=8.64$, $p<.05, d=0.66$, respectively.

\section{Discussion}

On the basis of reactance theory, I predicted that participants in the warning-label condition would want to taste the full-fat cream cheese more than would participants in the information-label condition. The results were consistent with this hypothesis (although they were not quite

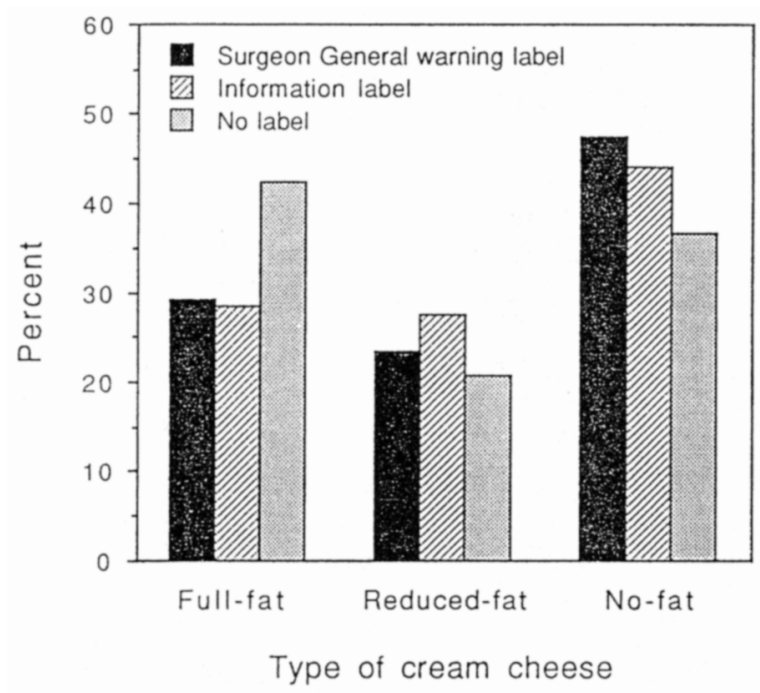

Figure 2. Effects of warning and information labels on consumption of full-, reduced-, and no-fat products. Capped vertical bars denote one standard error. significant). Warning people about the harmful effects of fatty products only made them want to eat the fatty product more.

I expected participants in the warning- and informationlabel groups to choose the full-fat cream cheese less often than participants in the no-label group. Because the harmful effects of fatty foods are credible and well-known, I did not expect the warning- and information-label groups to differ. The results were consistent with these predictions. Although a warning from an authoritative source made people want to eat the fatty product more, they chose not to eat it. Perhaps it sounds less preachy for the U.S. Surgeon General to warn people about the harmful effects of fatty foods than to warn them about the harmful effects of violent media.

The contrasting results between the preference and the actual behavior measures is quite instructive with regard to the potential effectiveness of labels and warnings. It does caution one to take studies that suggest warning labels are ignored with a grain of salt. Warning labels may have considerable influence on behavior in situations in which there are clear low cost behavioral alternatives that are reasonably (though somewhat less) satisfactory. In such cases, however, information labels might be at least as effective as warning labels if the risk is credible and well-known.

Some interesting sex differences also emerged in the present study. It is well-known that women are more concerned about consuming fatty foods than men are (e.g., Dowd \& Peel, 1992; Rodin, Silberstein, \& StriegelMoore, 1984; Wardle \& Beales, 1986). Thus, eating the no-fat cream cheese would be the norm for women. Over half of the women in the present study adhered to this norm - more than double the number of men who did. Those women who chose the fattier cream cheeses, in comparison with men, rated them as tastier. The women who ate higher fat cream cheese probably did so for one of two reasons: (a) They really liked fatty cream cheese, or (b) eating something they weren't supposed to made it especially yummy. The latter reason is consistent with forbidden fruit theory.

Although the warning label appears to have aroused reactance in participants, this can only be inferred because no measures of perceived threat to personal freedom were included in the study. The omission of such measures was intentional because I thought that they would only serve as demand characteristics for participants (see Orne, 1962). If measures of perceived threat to personal freedom had been included, participants probably would have figured out that the actual purpose of the study had something to do with warning labels, guessed what the experimenter was trying to predict, and behaved in a manner that would either support or refute experimenter's predictions. As it was, none of the 360 individuals who partici- 
pated in the study admitted to guessing the true purpose of the study.

Reactance may not be the only factor leading to a "boomerang" effect for warning labels. One alternative explanation for the present results is that warning labels enhance the sense of excitement and risk taking associated with consuming potentially harmful products. The present results, however, seem more consistent with reactance theory than with this alternative explanation. It seems less plausible that higher fat food seemed more attractive when it was labeled as dangerous.

One potential problem with the present study is that the warning label confounds the source of the warning (i.e., U.S. Surgeon General) with the personal risk to the consumer (i.e., heart disease). Thus, it is not possible to tell which factor contributes most to reactance. This is a naturally occurring confound, however, and it does serve to strengthen the warning label manipulation.

Future research might investigate health risks that are less familiar. It would also be desirable to unconfound the various elements of warnings (e.g., authoritative source, explicit link to personal risk, behavioral recommendation) to investigate which factor contributes most to reactance. Future studies could also include mediators (e.g., measures of threat to personal freedom) and moderators (e.g., individual difference measures of reactance) to clarify whether responses to warning labels are based on psychological reactance.

In summary, information labels seem to be at least as effective as warning labels in influencing people to avoid unhealthy products, at least when the risk is credible and familiar. Although people don't mind being informed about the potentially harmful risks associated with products, they don't like to receive unwanted advice about how they should behave. Warning people about unhealthy products may only make them want the products more.

\section{References}

Aaron, J. I., Mela, D. J., \& Evans, R. E. (1994). The influences of attitudes, beliefs and label information on perceptions of reduced-fat spread. Appetite, 22, 25-37.

Brehm, J. W. (1966). A theory of psychological reactance. New York: Academic Press.

Brehm, J. W. (1972). Responses to loss of freedom: A theory of psychological reactance. Morristown, NJ: General Learning Press.

Brehm, S. S., \& Brehm, J. W. (1981), Psychological reactance. New York: Wiley.

Broder, J. M. (1997, March 5). Warning: A Batman cape won't help you fly. New York Times, pp. A1, C2.
Bushman, B. J., \& Stack, A. D. (1996). Forbidden fruit versus tainted fruit: Effects of warning labels on attraction to television violence. Journal of Experimental Psychology: Applied, 2, 207-226.

Christenson, P. (1992). The effects of parental advisory labels on adolescent music preferences. Journal of Communication, 42, $106-113$.

Dowd, D., \& Peel, J. C. (1992). Dietary fat reduction practices by college males and females. College Student Journal, 26, 231-236.

Gershoff, S. N. (1995). Nutrition evaluation of dietary fat substitutes. Nutrition Reviews, 53, 305-311.

Innes, J. M., \& Zeitz, H. (1988). The public's view of the impact of the mass media: $T$ test of the 'third person' effect. European Journal of Social Psychology, 18, 457-463.

Jones, A., Greaves, K., \& Iliffe, S. (1992). Health protective behaviour and knowledge of coronary heart disease risk factors in a general practice population. Medical Science Research, 20,71-73.

Miller, A. (1989, September 11). Diets incorporated. Newsweek, $114,56-60$.

Orne, M. T. (1962). On the social psychology of the psychological experiment: With particular reference to demand characteristics and their implications. American Psychologist, 17, $776-783$.

Rodin, J., Silberstein, L., \& Striegel-Moore, R. (1984). Women and weight: A normative discontent. Nebraska Symposium on Motivation, 32, 267-307.

Snyder, L. B., \& Blood, D. J. ( 1992) . Caution: Alcohol advertising and the Surgeon General's alcohol warnings may have adverse effects on young adults. Journal of Applied Communication Research, 20, 37-53.

Solheim, R. (1992). Consumer liking for sausages affected by sensory quality and information on fat content. Appetite, 19, 285-292.

Stafleu, A., de Graaf, C., van Staveren, W. A., \& de Jong, M. A. (1994). Attitudes towards high-fat foods and their low-fat alternatives: Reliability and relationship with fat intake. Appetite, 22, 183-196.

Vasey, M. W., \& Thayer, J. F. (1987). The continuing problem of false positives in repeated measures ANOVA in psychophysiology: A multivariate solution. Psychophysiology, 24, $450-458$.

Wardle, J., \& Beales, S. (1986). Restraint, body image and food attitudes in children from 12 to 18 years. Appetite, 7, 209217.

Wicklund, R. A. (1974). Freedom and reactance. Potomac, MD: Erlbaum.

Williams, S. R., \& Worthington-Roberts, B. S. (1996). Nutrition throughout the lifecycle (3rd ed.). St. Louis, MO: Mosby.

Received May 27, 1997

Revision received August 4, 1997

Accepted August 5, 1997 